\title{
O ACERVO COMO RIZOMA
}

Nilo da Silva Lima*

RESUMO:

Esse artigo se propõe a discutir como o conceito rizoma, criado por Deleuze e Guattari, mostra-se relevante aos estudos de acervos, uma vez que a crítica genética tem privilegiado, nos estudos contemporâneos de literatura, o ato de criação reunido e preservado nos acervos dos escritores, atentandose para os itinerários do movimento criador.

PALAVRAS-CHAVE: acervo, rizoma, ato de criação.

Segundo Jacques Ranciére (1996), na estética deleuziana estaria em jogo não tanto um pensamento estético sobre a arte, ou sobre a obra de arte, mas a estética como figura de pensamento. Essa estratégia implica um deslocamento tanto da obra quanto das séries teóricas que assim concebem a arte, para a trajetória por ela descrita Uma concepção estética que segundo Grésillon "se priva da noção de obra para melhor se debruçar sobre as aparas dos rascunhos, sobre 0 inacabado e o incerto, sobre esses processos sem fim, essas catedrais pereciveis construídas sobre a areia" (Grésillon, 1999: 22). Considere-se, ainda, que operando a partir desta ordem do devir e do poder do caos, uma vez que as "certezas" são deslocadas, privilegia-se uma leitura do ato de criação como um ato de resistência capaz de vencer a morte (Deleuze, 1999: 5-4) pela sua pluralidade, por seu poder de conexão que deflagra o processo de criação em vez da obra criada.

Sob o ponto de vista desse pensamento é que proponho considerar essa leitura do acervo, e mais especificamente, do acervo de Oranice Franco (1919-1999), que venho pesquisando e que se constituiu no objeto da minha Dissertação de Mestrado em Teoria da Literatura na Faculdade Letras da UFMG.

* Mestre em Letras: Literatura, História e Memória Cultural (Área de concentração: Teoria da Literatura), 2004. 


\section{EMTESE}

Belo Horizonte, v. 9, p. I-28I, dez. 2005

Oranice Franco é mineiro de Lima Duarte, onde nasceu em 2 de novembro de 1919. Ainda na infância, sua família foi morar em São João delRei, daí sua paixão pela cidade, pela sua história, sua gente, sua cultura; por Minas Gerais. Movido por essa paixão é que mais tarde se interessa pelo jornalismo, concebido como um exercício que the acenava com a possibilidade de reinvenção da multiplicidade dos sentimentos por essa territorialidade. Tanto que no final da década de 30, foi para Belo Horizonte, atraído pela intensa vida intelectual na capital mineira, como confessou em artigo de 1946, publicado no $2^{\circ}$ Anuârio do Rádio: "com os primeiros fios de barba, achei que era tempo de criar juízo. Arrumei as malas e fui para Belo Horizonte. Na capital mineira me ajuntei a outros poetas e desandei". Desse período o seu envolvimento com escritores como Murilo Rubião, Nilo Aparecida Pinto, Guilhermino César, Otto Lara Resende, Paulo Mendes Campos, João Etienne Filho e Rosário Fusco que viviam a Belo Horizonte do início da década de 40 , tão importante para o cenário intelectual e literário de Minas Gerais.

No entanto, como seu interesse era o jornalismo, mesmo tendo trabalhado como articulista na Folha de Minas e na revista A Mensagem, regressou a São João del-Rei, partindo imediatamente para o Rio de Janeiro, sendo admitido na Rádio Nacional em abril de 1940. Aí permaneceu até à sua aposentadoria em 1982, produzindo programas de rádio e escrevendo radionovelas com Ghiaroni, Mário Brasini, Alziro Zarur e Pedro Anísio, quando, então, voltou definitivamente para São João del-Rei, onde morreu em 2 de novembro de 1999, sozinho, em sua residência na Av. 8 de dezembro.

Oranice Franco produziu e publicou uma extensa obra, abrangendo poesia, contos, crônicas e radionovelas. Porém, com uma distribuição irregular, sua obra atingiu um público muito reduzido, o que faz dele um escritor praticamente inédito.

0 meu trabalho é, a princípio, resgatar, não apenas a obra publicada do escritor, mas o seu processo de criação. Recordo-me, aqui, de uma conferência sobre crítica genética em que a professora Cecília Almeida Salles se propôs a pergunta que inquieta muitos de nós que trabalhamos com essa abordagem crítica: "vocês acreditam que têm o direito de estudar aquilo que o escritor rejeitou?" Penso que a existência dos próprios acervos dos escritores provam que não se trata de uma 
rejeição. Por ela, eles certamente teriam apagado por completo os vestígios da criação. Trata-se, antes, de um esconderijo provisório dos desarranjos e dos derredores das folhas que poupam a obra, dos seus bastidores, do seu estado de nascimento. E que muitos artistas guardam na certeza de que esses traços do processo possam, de seu inacabamento, iluminar a própria obra.

0 pensamento deleuziano tem-se tornado num relevante instrumento de operação e compreensão daquilo que, a meu ver, pode também caracterizar o estudo de acervo não como uma metáfora, mas como um instrumento metodológico capaz de auxiliar na interpretação da multiplicidade de elementos em que se apresenta. 0 que, por vezes, tem sido relegado em favor de uma concepção genética que, mesmo tendo evoluído para uma "desconfiança do texto acabado" (Willemart, 2001:185), atentando-se para "a incompletude do saber e a dissolução do grande relato" (Cury, 1993: 92), ainda tem sido pouco apreendido no sentido de uma leitura que parte não só da busca e de uma tentativa de interpretação de uma gênese, mas da constatação do acervo como lugar, cada vez mais definido como algo da ordem do "feito de matérias diferentemente formadas, de datas e velocidades muito diferentes", com "linhas de articulação ou segmentaridade, estratos, territorialidades, mas também de fuga, movimentos de desterritorialização e desestratificação" (Deleuze e Guattari, 1995: 11). 0 que por outro lado o aproxima também do "conjunto variado de coleções e objetos pessoais dos escritores que convidam sempre a uma viagem prazerosa do olhar, estabelecendo certas relações entre o presente e o passado, entre um mundo visível e um mundo invisível que procuramos recuperar como pesquisadores" (Marques, 2000: 31). Desse modo, penso que o privilégio dado a esse olhar crítico que destaca a capacidade de produção de fragmentos, a produção não só de um texto conetivo, mas uma compreensão do próprio ato de criação como um "processo sígnico" (Salles, 2003: 2) tem proporcionado uma compreensão da literatura como lugar de conjunção de fluxos, que é o que "faz dela o lugar de tentativas sempre renovadas" (Blanchot, 1984: 215), não um mero poço de memória, duplamente estanque: no sentido de algo parado, completo, estagnado, como também no sentido de esgotado, em que não há mais movimento, o que ciclicamente 0 remete à estagnação. 


\section{EM TESE}

Belo Horizonte, v. 9, p. I-28I, dez. 2005

No acervo, mais do que apenas evocação, aplica-se o conceito deleuziano de rizoma. As primeiras edições com as alterações operadas pelos escritores, a correspondência, os recortes de jornais e revistas, os papéis avulsos e os rascunhos formam, assim, o processo rizomático.

Se um rizoma é sempre conectável, não há, portanto, um eixo genealógico único, uma genealogia definidora de uma origem, mas agenciamentos. Ora, num acervo, além da conexão entre a multiplicidade, que the é própria e em que se apresentam seus elementos, há uma segunda rede de conexão que é a do acervo com outros agenciamentos como os da história, os da literatura e os da cultura, num movimento de contínuo deslocamento, incompletude e renovação.

0 resgate desse fio de conexão estabelecido entre o processo de criação de Oranice Franco e a produção literária e cultural do modernismo dos anos 40, sobretudo se pensada a partir de escritores mineiros como, Murilo Rubião, Nilo Aparecida Pinto, Carlos Drummond de Andrade, Autran Dourado, Otto Lara Resende, Fernando Sabino, permite-nos lançar luzes sobre a experiência pessoal vivida e tornada experiência de uma escrita transitada por uma espécie de diáspora mineira, cuja contribuição ao Modernismo ainda não foi de toda entendida, nem concluída, até mesmo pelo próprio aspecto rizomático do Modernismo que dispõe de uma multiplicidade de linhas de fuga do que até aqui o tem definido, por vezes, impropriamente como um movimento literário com princípio, meio e fim, sem que se atente, ainda muito para os seus múltiplos desdobramentos.

Quanto mais se desenvolve a pesquisa de um acervo, mais o pesquisador se aproxima da consciência de que, mesmo pertencendo a um autor, no conjunto de seus elementos e na cartografia de suas conexões, ele se impõe como "um objeto socialmente construído que sobrepassa em intenções de sentido e as valorações de seus encarregados. É um potencial semântico-pragmático à espera de sujeitos que o acionem" (Bordini, 2004: 3). É esse paradoxo que leva o pesquisador a procurar ou que o possui de uma espécie de mal de arquivo, "um arder de paixão, um desassossego incessante e interminável de procurar o arquivo onde ele se esconde, um desejo compulsivo, repetitivo e nostálgico" (Derrida, 2001: 118), numa ação perseguidora, apaixonada, paciente, prazerosa e repetitiva que opera por deslocamentos do sujeito e por reconhecimento de suas funções. 
A multiplicidade se apresenta não apenas na organização constitutiva do acervo, como no desencadear dos estudos de seus elementos em conexão com outras partes do rizoma em que ele se constitui. Nesse sentido, o processo de criação de Oranice Franco é atravessado por uma pluralidade de vozes que já trazem a característica de um lugar onde teoria e prática convivem sem a ocorrência de um território de fronteiras excludentes. É como se ao estudioso fosse dado flagrar a escritura em seu estado de nascimento.

0 processo é, portanto, diferente da obra pronta, mesmo porque uma obra nunca se conclui de fato. A obra é sempre um exercício reiterado do escritor de se ver como uma terceira pessoa, como um outro. A consciência de que o "eu" são outras formas de pensar, de sentir, de ser. Daí talvez a razão mais contundente da fundação da cidade rizomática Lagoa Mansa como um topos da especificidade do próprio ato criador fluindo e confluindo para a multiplicidade, para pluralidade do sujeito que escreve, rabisca, corrige reescreve, anota, 1ê, multiplica-se, foge.

Se o rizoma é múltiplo, conectável a uma pluralidade de outras cadeias sígnicas, ele é também da ordem da ruptura. Ou seja, pode ser quebrado, rompido em qualquer lugar e, considerando a multiplicidade de conexões, ser retomado segundo qualquer uma de suas linhas: um devir-acervo. Eis o grande desafio do estudioso de fontes primárias: 1idar com um objeto, que é devir-objeto. Assim, uma folha "achada" no meio de um livro que foi lido, a dobra de um jornal anotado nas margens, a rasura num manuscrito, tudo pode se conectar a outros agenciamentos com os quais o estudioso ainda que, de certa forma prevenido, depara e se angustia. Todavia, é essa angústia que move sua abordagem do literário; dela se nutre e, é a partir dela que trará à cena do pensamento contemporâneo, não a obra acabada, que nem existe, mas os meandros do ato de criação, que apontam para uma espécie de fuga da literatura para o seu exterior, recolocando-a de encontro com o que mais a define: 0 processo, o contínuo fazer-se, o inacabamento.

A dificuldade dos estudos em acervos, por outro lado, é também a de lidar com a abordagem desse sistema rizomático, dessa rede de criação que se rompe e se conecta continuamente. Cada elemento do acervo é ao mesmo tempo uma 


\section{EM TESE}

Belo Horizonte, v. 9, p. I-28I, dez. 2005

linha de segmentariedade e uma linha de fuga. E a sua leitura só se torna relevante se se considera a multiplicidade de suas conexões, atentando-se para uma compreensão das reações exercidas no processo de criação. Como, aliás, ressalta Júlio Castañon Guimarães (2000: 40): "para além do muitas vezes árduo e fundamental plano da decifração e da descrição, há sempre pelo menos um horizonte de expectativa no sentido das articulações, dos comentários, das interpretações". Por isso aquele "cartãozinho" que Oranice Franco recebeu do poeta Manuel Bandeira, em 29 de maio de 1954, ainda que o estudioso queira The atribuir um certo poder histórico adquirido pelas conexões que estabelecem com o poeta que se tornou Manuel Bandeira - o sujeito, o poeta e a obra, constituindo um agenciamento - só a partir de uma retomada dessa ruptura com outras conexões do próprio acervo, da historiografia literária, da história e da cultura, tem-se, de fato, a relevância do acervo como lugar de conexões, como estado de cruzamento de saberes. Então, cada elemento faz rizoma com o acervo, enquanto que o acervo faz rizoma com o escritor desterritorializandoo e aumentando-The o território, que se por um lado opera por esta linha de ruptura, por outro, opera-se também pelos agenciamentos que constituem o acervo.

Malgrado a paixão que não evita as ciladas, o estudioso há se tornar um operador de plantas, um conjugador e operador de fluxos desterritrorializados. Há se ater a provisoriedade, pois as conexões são múltiplas e não cessam. Há que se aplicar à paciência "para sair efetivamente em busca dos documentos dispersos em meio ao próprio processo; paciência para decifrar, classificar, transcrever e interpretar os bastidores da criação" (Grésillon, 1999: 30).

Assim, o que mais interessa ao estudioso do acervo deve ser avançar para além do "flagrar o escritor no momento da escritura" (Cury, 1993: 90) e atentar para o que se deflagra a partir de um mapeamento do acervo e do seguir atentamente a multiplicidade de suas conexões, aproximando-se de uma compreensão dos procedimentos geradores da criação.

Por essa abordagem insisto pensar a crítica genética, que nas últimas décadas avançou, sobretudo, no sentido de incluir na compreensão da 
obra de um escritor o seu processo de criação a partir do privilégio de um olhar que resgata o acervo, não para apontar um eixo genético sobre 0 qual toda obra se organizaria, mas no sentido de lê-1o em sua multiplicidade como lugar em que, privilegiadamente, a obra possa ser apreendida na complexidade de seus elementos com distinção para o papel do itinerário da criação na sua relação com o próprio projeto artístico.

0 acervo sempre acena ao pesquisador com essa sensação de se mover em meio às coisas; em meio aos papéis, em meio ao processo de criação. Com esse deslocamento da origem e do fim, não por não existirem, por insignificância, mas por virem conectados ao movimento criador, a pesquisa de acervo é sempre esse mover-se entre. E é exatamente esse movimento e por esse movimento que o acervo se torna sempre numa questão do futuro e não num mero e nostálgico resgate do passado. Menos ainda o passado como um souvenir ou idéia, mas como matéria de um pensamento que opera pelo contraditório, desfigurando a ilusão de obra acabada, e instaurando, como espaço privilegiado de estudo, não a obra, mas o próprio ato de criação, que se desloca pela multiplicidade de conexões que, por sua vez também, não cessam de estar sempre em curso. Assim é um acervo: um objeto sempre por se fazer, sempre em conexão com os seus próprios elementos de constituição e com os elementos de constituição da escrita de sua trajetória espaço-temporal.

ABSTRACT:

This article intends to discurs how the rhizome concept comes to be relvant to the studies colletions, once the genetic cristicism has privileged, in the contemporaneous studies of literature the act of creation, gathered and preserved in the writers' colletions considering the itineraries of the creative movement.

KEY WORDS: collection, rhizome, act of creation. 


\title{
EM TESE
}

Belo Horizonte, v. 9, p. I-28I, dez. 2005

\author{
REFERÊNCIAS BIBLIOGRÁFICAS
}

BENJAMIN, Walter. A hora na era da reprodutibilidade técnica. Magia e técnica, arte e política. Trad. Sérgio Rouanet. São Paulo: Brasiliense, 1976, p. 165-196.

BLANCHOT, Maurice. O livro por vir. Trad. Maria Regina Rego. Lisboa: Relógio d'Água, 1984.

- Les intelectuels en questions: ébouche d'une reflexion. Paris: Faubris, 1996.

BORDINI, Maria da Glória. Acervos literários e história da literatura. Disponivel em : <www.documentos $\backslash$ bordini.htm>. Acessado em: 16. abr. 2004.

CURY, Maria Zilda Ferreira. A pesquisa em acervos e 0 remanejamento da crítica. Manuscrítica. São Paulo: Annablume, n. 43, p. 79-93, 1993.

DELEUZE, Gilles; GUATTARI, Félix. Mil platôs: capital ismo $e$ esquizofrenia. Trad. Aurélio Guerra Neto e Celia Pinto Costa. Rio da Janeiro: Editora 34, v.1, 1995.

DELEUZE, Gilles; PARNET, Claire. Dialogues. Paris: Flamarion, 1977.

. Foucault. Trad. Cláudia Sant'Anna Martins. São Paulo: Brasiliense, 1998.

- 0 ato de criação. Trad. José Marcos Macedo. Folha de S. Paulo. Caderno Mais, 27 jun. p. 5-4, 5-5, 1999.

- Faile et feux locaux. L'île désert et autres textes. Paris: Minuit, 2002, p. 217-225.

DERRIDA, Jacques. Mal de arquivo: uma impressão freudiana. Trad. Cláudia Morais Rego. Rio de Janeiro: Relume/Dumará, 2001.

FRANCO, Oranice. Minha rua de Minas. Rio de Janeiro: A Noite, 1949.

- Lagoa Mansa. Rio de Janeiro: Conquista, 1972.

GUIMARÃES, Júlio Castañon. Manuel Bandeira e Carlos Drummond de Andrade: o poema do periódico ao livro. Ipotesi: revista de estudos literários, Juiz de Fora: UFJF, n. 2, v. 4, p. 39-47, 2000.

GRÉSILLON, Almuth. Devagar: obra. Trad. Júlio Castañon Guimarães. Rio de Janeiro: Fundação Casa Rui Barbosa, 1999, p. 21-47.

RANCIÉRE, Jacques. Exist-t-il une esthétique deleuzienne? Gilles Deleuze: une vie philosofique - reencontres internationals. Direction Eric Alliez. Rio de Janeiro, 1996, p. 525-536.

SALLES, Cecîlia de Almeida. Redes de criação. Disponível em <www.pucsp.br>. Acessado em: 25 mar. 2003.

WILLEMART, Philippe. Crítica genética e historiografia literária. Manuscrítica. São Paulo: Annablume, n. 10, p. 165-185, 2001. 